\title{
Agua para mi molino. Lectura de la controversia Bello-Lastarria a través de Bertolt Brecht y Carlo Ginzburg
}

\author{
Andrés Kalawski \\ Escuela de Teatro \\ Pontificia Universidad Católica de Chile
}

\section{Preguntas de un historiador ante un libro}

La publicación de El queso y los gusanos: El cosmos según un molinero del siglo XVI, de Carlo Ginzburg, en 1976, supuso un sacudón de repercusiones perdurables en la historiografía (Julián Delgado y Rodrigo González Tizón). Se trató de un libro elogiado por la crítica especializada y de altas ventas y difusión, combinación siempre sorprendente. Es un trabajo entretenido y bellamente escrito, lo que no es poco. El libro es varias cosas más: es un relato diestro acerca de parte de la vida de un molinero friulano del siglo $X V I$; es una indagación respecto de la manera de escribir historia; y es una demostración de la posibilidad del rescate de las voces del pasado, como pide el poema de Brecht que el libro invoca al inicio (el poema "Preguntas de un obrero ante un libro", de 1936). Con evidente autoironía, el libro cierra refiriendo al mismo poema: "Sabemos muchas cosas de Menocchio. De este Marcato o Marco -y de tantos otros como él, que vivieron y murieron sin dejar huellas- no sabemos nada" (Ginzburg, El queso y los gusanos 231).

Para el que busca huellas es difícil no ir dejando las propias y el que busca cosas enterradas se tienta a esconder tesoros. La relación artística (técnica, si se quiere) entre Ginzburg y Brecht es mucho más profunda que estas asas literarias. Puede rastrearse la preocupación de Ginzburg por el artificio preferido de Brecht, el extrañamiento y su conexión con la larga tradición materialista y luego científica, así como con la cultura popular (Ginzburg, «Making Things Strange: The Prehistory of a Literary Device»), pero también es evidente su insistencia en mantener un discurso fragmentario, una de las grandes cruzadas brechtianas contra la textura lisa que se esperaba del realismo socialista. Natura facit saltus (Brecht 46). Advierto desde ya: este texto también salta y vamos a ir al teatro y al siglo XIX chileno buscando rastrear nuestra lectura de la historia.

Se trata de una afinidad ideológica y no solo estética. La posibilidad de un discurso moderno (científico, diría Brecht) que continúa y recupera elementos de la cultura popular. Y a veces la ideología manda. A pesar de toda la pericia y la imaginación desplegada por Ginzburg, el texto termina reduciendo a Menocchio a representante de una cultura popular que nos llega por su boca. Es un paso doloroso pero necesario para el programa ideológico del libro. Ginzburg no lo oculta. Luego de insistir en la singularidad del protagonista, el autor pregunta: "¿Hasta qué punto podemos considerar representativo a un personaje tan poco común como el de un molinero del siglo XVI que sabía leer y escribir? Y, además, ¿representativo de qué?" 
(Ginzburg, El queso y los gusanos 85). Evadiendo la idea de la cultura popular como almacén de contenidos, se gira hacia el tamiz de lectura, al generador de ideas. Es un vuelco brillante y bien justificado que termina, sin embargo, anulando la individualidad del molinero y devolviéndolo al estado de documento, de prueba, más que de persona. En eso Ginzburg va traicionando su intento de corregir a Foucault, quien prefiere pensar en las clases subalternas como estructuralmente silentes, fuera del archivo, de la cultura incluso. En la obra de Ginzburg se les devuelve la palabra, pero terminan convertidos en representantes, es decir, en signo de algo que los excede, invisibles de nuevo.

Hablamos de un autor sagaz que ha sido crítico y reflexivo de la larga tradición investigativa -inquisitorial- en la que se encuentra. ${ }^{1} \mathrm{Ha}$ escrito de la relación entre antropología e inquisición, y apremiado por el encarcelamiento de su amigo Adriano Sofri, 2 el rol de la historiografía respecto de la justicia. Incluso en su mirada respecto de la manera de los jesuitas de recurrir al pasado romano para entender el imperio chino hay una crítica a la función de la historiografía (Ginzburg, Gesuiti in Cina (secolo XVIII): documenti vecchi e nuovi).

Quizás la dificultad está en que, al menos en este libro, Ginzburg lee, pero no lee cómo lee. Esta recursividad se espera de un actor brechtiano: mientras actúa, mira su propio cuerpo de actor, se sorprende de sus gestos y guía la mirada crítica del espectador. Al menos eso se supone que pasa cuando la función resulta bien.

Para saber cómo leemos nosotros, tenemos que volver a nuestra propia tradición, así como Ginzburg discute la suya. Quizás no baste para no caer en la misma trampa de siempre, pero servirá al menos para caer con los ojos abiertos. Actuar mirándose actuar. Ser consciente de la propia posición, como se pide a la historiografía académica. Dejemos un momento a la Europa de la Reforma y volvamos a nuestro siglo XIX, a una controversia historiográfica aparentemente zanjada, añeja, tediosa: la disputa entre Andrés Bello y José Victorino Lastarria acerca de la manera en la que se debe escribir la historia.

\section{La misma polémica, pero otra}

El intercambio de opiniones por la prensa a propósito de la memoria Sobre la influencia social de la conquista i del sistema colonial de los españoles en Chile que José Victorino Lastarria presentó a la Universidad de Chile en 1844, fundido con otro intercambio más largo, el generado por la presentación en 1847, nuevamente por parte de Lastarria, de un Bosquejo histórico la constitución del gobierno de Chile durante el primer período de la Revolución, desde 1810 hasta 1814, se ha vuelto con el tiempo la piedra de toque de

\footnotetext{
1 Acerca de la tradición investigativa inquisitorial, véase: Carlo Ginzburg. "El inquisidor como antropólogo". El hilo y las huellas: Lo verdadero, lo falso, lo ficticio. Fondo de Cultura Económica: Madrid, 2010: 395-411.

2 Acusado de ser uno de los autores intelectuales del asesinato del comisario Luigi Calabresi.
} 
la historia de la historiografía chilena, como han señalado abundantemente historiadores plenamente insertos en la tradición académica de la historiografía (Woll 187; López 203; Colmenares 189; Krebs 191).

Resulta difícil no ver en la entronización de este debate una respuesta, desde la historiografía, al mito de la creación de la nación: a un surgimiento brusco de la nación, mediante la guerra de independencia, seguiría un nacimiento igualmente brusco y violento, de una historiografía nacional. El prestigio intelectual y el peso político de los involucrados -Andrés Bello, José Victorino Lastarria, Jacinto Chacón y Antonio Varas-, no hace sino volver más seductora la pugna. Remata el cuadro el aparente triunfo de las opiniones de Bello. Volveremos sobre el carácter aparente, bien del triunfo, bien de sus opiniones. El asunto es que la corriente intelectual que predominó parece además continuar imperando, de manera que los historiadores chilenos actuales pueden sentirse justamente identificados con el bando vencedor $y$ admirar la batalla desde cómodo puesto.

Hasta aquí todo parece calzar en cómo se ha relatado la controversia. Todo parece calzar y eso, curiosamente, no parece alarmar a nadie. ¿Desde cuándo los eventos históricos calzan perfectamente con un molde mítico, desde cuándo es función de los historiadores autodramatizar su origen de manera tranquilizadora aprovechando la feliz circunstancia de que el pasado les da la razón? Una última coincidencia, en vez de aumentar el prestigio de la controversia, debiera autorizarnos a la vez la sospecha y la contextualización. Ricardo Krebs observa que el debate chileno de 1844-8 repite el esquema del debate poco anterior en Alemania entre Ranke y Leo (191). Sin embargo, los protagonistas chilenos, a pesar de ubicarse en idénticas posturas, no invocaron nunca, hasta donde sabemos, el de sus pares alemanes.

Ante este curioso fenómeno, podemos pensar dos cosas excluyentes entre sí. En primer lugar, que este debate es intrínseco a la disciplina y no requiere contexto, es estructural, inevitable, ahistórico incluso. En segundo lugar, que la identidad entre ambos debates es ilusoria, que la piedra fundante de la profesionalización historiográfica chilena ha sido elevada al rango de mito fundacional mediante lecturas sesgadas y perspectivas forzadas. Esta segunda idea es la que intentaremos demostrar aquí.

Hasta ahora, prácticamente todas las revisiones de la polémica han asumido que Bello y la comisión que juzgó el trabajo de Lastarria, de un lado, y Lastarria y Chacón, por otro, están perfectamente alineados en bandos opuestos. Así, se han respetado oposiciones de los polemistas como inducción / deducción, ad narrandum / ad probandum y filosofía / detalle, lo que, en vez de aclarar conceptos, ha terminado consolidando malentendidos que posibilitan que respecto de este asunto se reciten mantras más que hacer historia.

No se trata, por supuesto, de negar la existencia de la polémica. Hubo un intercambio severo de ideas de todos los involucrados, se mencionó el método histórico, por supuesto, pero la vida estaba en otro lado. Se estaba forjando una guerra civil, la discusión acerca de la legitimidad del Estado y su Constitución, de la forja de una nación libre o la construcción de una sociedad ordenada, asumiendo que ambas no son siempre compatibles. Chacón 
acusó a Bello de ser un tirano mientras insinuaba críticas a la Constitución. Demasiados historiadores han tomado las estrategias de encubrimiento del problema como si fueran el meollo del asunto. Qué tentador es olvidar que todo lo dicho es dicho por alguien y que las fuentes no son siempre sinceras ni perfectas en su expresión.

El 22 de septiembre de 1844, un joven José Victorino Lastarria (tenía 27 años) presentaba ante la Universidad de Chile, en sesión solemne, su memoria histórica Investigaciones sobre la influencia de la conquista y sistema colonial de los españoles en Chile. En su trabajo, Lastarria no refiere episodios particulares del período que trata:

"[...] abria preferido aceros la descripción de aqellos sucesos eróicos o episodios brillantes qe nos refiere nuestra istoria, para mover vuestros corazones con el entusiasmo de la gloria o de la admiración, al ablaros, de la cordura de Colocolo, de la prudencia i fortaleza de Caupolican, de la pericia i denuedo de Lautaro, de la ligereza y osadia de Painenancu; pero ¿qé provecho real abríamos sacado de estos recuerdos alagüeños?" (Lastarria, Investigaciones sobre la influencia de la conquista y sistema colonial de los españoles en Chile 33).

En vez de ello, Lastarria se lanza a evaluar las características y consecuencias del sistema colonial español en Chile. Afirma que el sistema administrativo colonial español ha mantenido al pueblo en la "más brutal y degradante ignorancia" (Lastarria, Investigaciones sobre la influencia de la conquista y sistema colonial de los españoles en Chile 39) y que el pueblo habría quedado "profundamente envilecido, reducido a una completa anonadación y sin poseer una sola virtud social, a lo menos ostensiblemente porque sus instituciones políticas estaban calculadas para formar esclavos" (Lastarria, Investigaciones sobre la influencia de la conquista y sistema colonial de los españoles en Chile 67). La revolución de independencia, que habría iniciado el camino de la libertad, no habría destruido aún gran parte de este sistema, que continuaría imperando en momento de la redacción de la memoria y que constituiría la gran traba que Chile debía superar.

Muchos años después, en 1878, Lastarria (Recuerdos Literarios) afirmaría que la recepción de su obra no fue la esperada y que aunque Bello mismo le había encargado el trabajo, no habría quedado conforme con el resultado. Una fila de investigadores, de Olga López a Cristián Gazmuri, ha dado por cierta la afirmación de Lastarria y así ha leído los dos artículos, del 8 y 15 de noviembre del mismo año, en que Andrés Bello se refirió a la memoria de su pupilo. Se ha puesto énfasis en la diferencia entre el rector de la universidad, entonces de 63 años, y el profesor de la misma (Sacks 202), interpretando las discrepancias en gran parte como un conflicto entre conservadores y liberales y como choque generacional.

Es cierto que Bello resiente la idea de ser nada más que un producto de un sistema envilecido, como describe Lastarria a la burocracia colonial, de la que Bello emerge. "Jamás un pueblo profundamente envilecido, completamente 
anonadado, desnudo de todo sentimiento virtuoso, ha sido capaz de ejecutar los grandes hechos que ilustraron las campañas de los patriotas [...]" (Bello 84). También es cierto que el inicio del primer artículo, que hace preterición acerca de los méritos de la memoria presentada, ha sido interpretado, sin justificación, como mera forma, puro refinamiento. Así se afirma la idea de que se estaba produciendo una genuina polémica, más que un intercambio profesional entre académicos con coincidencias profundas.

El siguiente paso, que algunas veces se deja pasar, es un paso en silencio. Otras memorias se siguieron presentando (Gazmuri y Woll informan de ellas) y no se elevó el intercambio de opiniones respecto de ellas al rango de debate fundacional. En 1847 la Facultad de Filosofía y Humanidades de la Universidad de Chile abrió un concurso concerniente al método apropiado de escribir la historia. La competencia fue declarada desierta.

No deja de ser curioso, cuando se exalta el poder absoluto de Bello para regir la Universidad, la adhesión al parecer mayoritaria a sus supuestos historiográficos que, habiendo premio de por medio, un concurso fácil de ganar haya terminado desierto. ¿Es que era imposible tomar partido por lo que el rector quería que se dijera y ya había delineado? ¿Es que todos tenían mejores cosas que hacer, que la investigación histórica podía jugar un rol político, como destaca Woll (passim) mientras la reflexión disciplinar no podía servir al mismo propósito? ¿Sería que la obviedad aparente del método histórico impedía su explicitación? No sabemos.

El mismo año, en un primer concurso anual de textos históricos organizado por la universidad, José Victorino Lastarria obtiene el premio por su Bosquejo histórico de la constitución del gobierno de Chile, durante el primer período de la revolución, desde 1810 hasta 1814. Aquí las cosas se complican. La imagen de un Lastarria rebelde y castigado por la autoridad, que gana un concurso sumamente oficial es levemente contradictoria. Es verdad que Lastarria fue el único concursante, pero sabemos que el premio bien podría haberse declarado desierto.

El texto, aunque más acotado en su arco temporal, retoma los mismos asuntos de la memoria. La incapacidad para sacudirse del sistema social instalado por la Colonia española aun durante la emancipación por las armas. Aunque hay aquí un tiempo más breve, sigue sin entrar en detalles, casi no hay fechas, pocas fuentes y pocas notas.

Al texto de Lastarria respondió el rector con un artículo en El Araucano, el 7 de enero de 1848. Es en este artículo donde aparece el signo más perturbador. Al modelo histórico filosófico propuesto por Lastarria, opone Bello una lista de grandes nombres: menciona a Tucídides y Tácito junto con Robertson, Gibbon y Prescott. ¿Podría pensarse en un conjunto más heterogéneo? Esta lista no se puede considerar seriamente. Es una corte de santos, un panteón, pero no un modelo.

Jacinto Chacón, amigo de Lastarria y profesor del Instituto Nacional, escribió el prólogo para la publicación del Bosquejo... y publicó en El progreso el 29 de enero de 1848 "Cuestión sobre la ciencia histórica". Aquí introdujo 
los términos ad probandum y ad narrandum, siendo partidario del primero, y afirmó que la respuesta de Bello sería un "Ejercicio intolerante de la autoridad universitaria contra la libertad de escribir la historia" (Dager 122). A la acusación contra su autoridad, Bello no se refirió. Lastarria tampoco dijo nada. Nada por escrito, al menos. Se centraron en la pertinencia de los métodos de narración y prueba y se confundieron homologándolos a la inducción y la deducción. La narración no es inductiva a menos que así se la use, convirtiéndola en prueba, lo que desharía la oposición anterior. Gente ofuscada, se ve.

Bello publicó un "Modo de escribir la historia" en El Araucano, el 28 de enero, siempre llamando a Chacón a leer más y mejor. Chacón respondió por El Progreso. Aquí el intercambio había escalado, pero es difícilmente atribuible a la discusión acerca de los métodos históricos, cuando Chacón había lanzado a la cara de Bello el ser un antilibertario. Llevando el argumento al ridículo, Jacinto Chacón dice que si los europeos tienen ferrocarriles, no habría por qué no importarlos para dar gusto al conocimiento generado en América que propugnaba Bello. Sería injusto atribuir a Lastarria esta misma visión. Años más tarde, como destaca Jocelyn-Holt (76), el mismo Lastarria prevenía contra los excesos y los abusos de la imitación. Bello contestó con una última vez, el 4 de febrero, con un "Modo de estudiar la historia". Después todos guardaron silencio respecto de estos asuntos, o dejaron de escribir de ellos, que no es lo mismo.

Esta es la discusión que se volvió canónica, esta es la reflexión que se ha tenido por fundante. Aunque la mayoría de los estudiosos han seguido la opinión que diera Barros Arana en 1905, declarando vencedor a Bello (Colmenares 3), al punto de considerar a Bello nuestro salvador,

"Los escritos de un Lastarria fueron, en su tiempo, aportes valiosos a la vida intelectual chilena y el mismo Bello reconoció generosamente sus méritos. Sin embargo, habría sido peligroso que Lastarria hubiese hecho escuela y que se hubiese impuesto una historiografía especulativa, fruto más bien de la imaginación personal que de la laboriosa búsqueda en los archivos, el examen crítico de las fuentes y el empleo riguroso de métodos objetivos. Gracias, en gran parte, a Andrés Bello, la historiografía chilena se organizó como ciencia" (Krebs 263).

Ciento cincuenta años después, Cristián Gazmuri insiste en el mantra del triunfo de Bello "[...] en la polémica tomó ventaja Bello y marcó así lo que sería la historiografía chilena decimonónica: positivista, erudita, narrativa, estrechamente apegada a las fuentes y poco amiga de interpretaciones" (56). Hay que tomar la afirmación de Gazmuri como la de quien, dedicado a la historia política, la historia importante para algunos, se siente heredero y continuador de esta misma tradición. Así, resulta perturbador que en la introducción del mismo libro, afirme:

"En el Chile colonial, [...] Chile fue una sociedad semimovilizada militarmente, debido a la casi interminable guerra 
contra los indios araucanos [sic]-la que se reanudaba periódicamente- que debió sostener la administración. Es así que el hecho de que Chile fuese lo que algunos autores han llamado "tierra de guerra", ciertamente ayudó a implantar la idea del "deber ser" social como un todo ordenado y jerarquizado.[...] También trabajó en favor de la existencia de una mentalidad proclive a aceptar la jerarquización social, privilegiar el orden y una autoridad política fuerte, el hecho de que la hacienda (hoy fundo) fuese la estructura social predominante [...]" (Gazmuri 43-44).

Esta es la introducción de un libro pertinente a la historiografía chilena. Si en algún lugar reinara Bello tendría que ser aquí. ¿No son estas las ideas de Lastarria? ¿No es la persistencia del sistema de haciendas lo que mantiene pasivo y sometido al campesino? También en entrevistas relacionadas con el libro el autor insiste en el aislamiento lastarriano de Chile, esta isla ¿No era que haciendo notas, visitando el archivo, íbamos a descubrir cosas nuevas, a salir del error de nuestros prejuicios?

\section{Saltos y notas: cambio en las convenciones historiográficas}

Más arriba también recordábamos la polémica entre Ranke y Leo (supra, sección 2). Esa polémica, que Krebs usa hábilmente para aumentar el prestigio de la disputa local, estuvo detonada por la publicación de los trabajos de Ranke en los que, además de insistir en el privilegio de lo particular y el detalle, afirmaba también que sus métodos innovadores volvían su narración, si no invulnerable, sí muy sólida. Esto, en parte, por la forma en que refería cada punto de su relato a las fuentes originales mediante un escrupuloso sistema de notas.

Según Grafton (129-30), la transformación de los métodos de investigación y de los resultados narrativos, en particular el de las notas al pie, son una sola y misma cosa. Aunque las notas por sí solas no prueben nada, han aparecido como un intento de los investigadores de dar cuenta del proceso de su investigación a la vez que de su resultado. Esta obligación de transparentar el proceso habría estado guiada en parte por la desconfianza creciente hacia la historia como disciplina en la Europa de los siglos XVII y XVIII, fascinada con la ciencia y por la necesidad de exhibir pruebas entre anticuarios enfrascados en disputas religiosas entre católicos y protestantes (111 y ss.).

Durante el siglo XIX, la historia se convirtió en un discurso hegemónico (Unzueta 220). Esta hegemonía se habría fraguado lentamente desde mediados del siglo XVI (Ginzburg, «Descripción y cita» 31). Ranke habría heredado, pulido y presentado como nuevas herramientas que llevaban mucho tiempo en el mercado. Lo que sí era nuevo, era la conciencia de este cambio, de una ruptura, una historia.

"Las citas, notas y signos lingüístico-tipográficos que las acompañan pueden ser considerados, en tanto que 
procedimientos tendientes a comunicar un efecto de verdad, como correlatos de la enárgeia. Desde luego, eran signos convencionales [...]. Pero la analogía de las funciones pone de relieve la diferencia de los instrumentos. La enárgeia estaba ligada a una cultura basada sobre la oralidad y la gestualidad; las citas al margen, los reenvíos al texto y los paréntesis angulares, a una cultura dominada por la imprenta. La enárgeia quería comunicar la ilusión de presencia del pasado; las citas enfatizan que el pasado solo nos es accesible de modo indirecto, mediado" (Ginzburg, 2010, pp. 49-50).

Es posible pensar que la resistencia de Lastarria a referir detalladamente episodios gloriosos se deba no solo a su deseo de elevarse por sobre el asqueroso datito, al modo de los filósofos ilustrados, sino también a que, en parte debido a este impulso de insistir en una forma historiográfica anterior a la gran conciencia de cambio, no encuentra función para el detalle. Y es que este es completamente inútil (Barthes 179). No está vinculado a la estructura del texto, sino a su relación con el género y con la recepción. Cuando la nimiedad deja de estar codificada culturalmente, el detalle se vuelve un intento por hacer sentir al espectador que solo quien conoce a tal punto lo que ocurrió puede saber tamaña pequeñez, creando así un "efecto de realidad" (Barthes 180). No sabemos qué distancia sentían con ese pasado Lastarria, Bello y Chacón. De nada sirve mirar sus fechas de nacimiento. La distancia con el pasado no depende del tiempo.

El cambio cultural que amarró detalle y objetividad terminó volcándose sobre sí mismo. Se sancionaba y trababa de esta forma la lenta operación de la modernidad de inventar el pasado como algo separado e inaccesible.

"Ese tema [que vencedores y vencidos hayan sido igualados en el polvo de la muerte] no era nuevo [siglo XVII]: nuevo era el recelo de evocar, gracias al virtuosismo retórico, el pasado como un todo consumado. En su lugar, comenzaba a aflorar la conciencia de que nuestro conocimiento del pasado es inevitablemente incierto, discontinuo, lagunoso: basado sobre una masa de fragmentos y ruinas" (Ginzburg, «Descripción y cita» 54).

Quizás Bello, formado en la versión dieciochesca y colonial de la tradición clásica, no pudo comprender hasta qué punto la modernidad estaba transformando esa cultura y cuánto él mismo empujaba ese carro. Para cuando Barros Arana en 1905 miraba hacia atrás y recordaba la polémica entre Lastarria y Bello, tampoco podía reflexionar acerca de la entronización de nuevas convenciones, aunque sí podía sentirlas. Buscando una causa a la que echar mano para explicar la uniformidad de criterio respecto de cómo debía ser la historia, ¿qué mejor que atribuirle al visionario Bello el triunfo?

En un ensayo que se ha vuelto célebre, Carlo Ginzburg (Indicios. Raíces de un paradigma de inferencias indiciales) intentó delinear una tradición de razonamiento sobre fragmentos, un "paradigma de inferencias indiciales". En otros lugares (El hilo y las huellas: Lo verdadero, lo falso, lo ficticio) ha apuntado la conexión posible entre el tipo de prueba con la que se construye 
el razonamiento histórico y un sistema expresivo que sería, o debería ser, también fragmentario.

Hay enorme atractivo en la construcción a saltos, como se vuelve atractivo el espejo que se quiebra y brilla convertido en pedacitos. Hay también un peligro. La idolatría de los fragmentos es la idolatría de los intersticios entre ellos. De la razonable desconfianza ante los razonamientos monolíticos es fácil pasar de la renuncia a la explicación del tránsito de un punto a otro.

He intentado aquí mostrar cómo la insistencia, a ratos contradictoria, de Andrés Bello respecto de lo saludable de determinada acción, no puede haber bastado para explicar que esa acción terminara imponiéndose de forma relativamente similar a como él lo quería. No hay aquí una explicación de cómo los historiadores chilenos decimonónicos absorbieron, asimilaron y quizás transformaron las nuevas convenciones generadas en Europa. Quizás porque las prácticas dejan pocas huellas en los archivos, huellas en los márgenes que no tomamos en cuenta tratando de reconstruir el hilo central; permanecen en los repertorios conductuales y allí se estratifican, se mezclan, se desvanecen. Para estudiarlas, quizás debamos abandonar en parte la tradición firme y forjada, los añosos originales, el archivo, suspender un momento las notas y volver a mirar lo que estamos haciendo nosotros mismos, ahora, al escribir.

\section{Obras citadas}

Barthes, Roland. "El efecto de realidad". El susurro del lenguaje. Más allá de la palabra y la escritura. Barcelona: Paidós, 1994.

Bello, Andrés. "Investigaciones sobre la influencia de la conquista y sistema colonial de los españoles en Chile. Memoria presentada a la Universidad en sesión solemne del 22 de septiembre de 1844 por don José Victorino Lastarria". Obras completas de don Andrés Bello. Vol. VII. Santiago: Pedro G. Ramírez, 1884. 71-88.

Brecht, Bertolt. Escritos sobre teatro. Barcelona: Alba, 2004.

Colmenares, Germán. Las convenciones contra la cultura: ensayos sobre la historiografía hispanoamericana del siglo XIX. Bogotá: Tercer Mundo Editores, 1987.

Dager, Joseph. "El debate en torno al método historiográfico en el Chile del siglo XIX". Revista Complutense de Historia de América 28 (2002): 97-138.

Gazmuri, Cristián. La historiografía chilena (1842-1970). Vol. 1. Santiago: Centro de Investigaciones Diego Barros Arana, 2006.

Ginzburg, Carlo. "Descripción y cita". El hilo y las huellas: Lo verdadero, lo falso, lo ficticio. Buenos Aires: Fondo de Cultura Económica, 2010. 19-54. El hilo y las huellas: Lo verdadero, lo falso, lo ficticio. Buenos Aires: Fondo de Cultura Económica, 2010.

El queso y los gusanos. Barcelona: Muchnik, 1997.

Conferencia "Gesuiti in Cina (secolo XVIII): documenti vecchi e nuovi". Biblioteca Nacional, 2008.

"Indicios. Raíces de un paradigma de inferencias indiciales". Mitos, emblemas, indicios. Morfología e historia. Barcelona: Gedisa, 1999.

"Making Things Strange: The Prehistory of a Literary Device". Representations 56 (1996): 8-28. 
Grafton, Anthony. Los orígenes trágicos de la erudición. Buenos Aires: Fondo de Cultura Económica, 1998.

Jocelyn Holt, Alfredo. "La Idea de Nación en el Pensamiento Liberal Chileno del Siglo XIX". Opciones 9 (1986): 67-68.

Julián Delgado, y Rodrigo González Tizón. "La revolución de Menocchio. El impacto historiográfico de El queso y los gusanos de Carlo Ginzburg". Rey Desnudo: Revista de Libros 3: 6 (2015): 228-56.

Krebs, Ricardo. "Bello y la Historia". Homenaje a don Andrés Bello con Motivo de la Conmemoración del Bicentenario de su Nacimiento. Santiago: Editorial Jurídica de Chile y Editorial Andrés Bello, 1982. 251-65.

Lastarria, José Victorino. "Investigaciones sobre la influencia de la conquista y sistema colonial de los españoles en Chile". Miscelánea histórica y literaria vol. I. Valparaíso: Imprenta de la Patria, 1868. 3-136. Recuerdos Literarios. Santiago: Imprenta de la República de Jacinto Núñez, 1878.

López, Olga. Una polémica sobre los métodos históricos. Ensayo sobre la influencia de Bello y Lastarria en la concepción de la historiografía tradicional. Valparaíso: Dirección General de Prisiones, 1945.

Sacks, Norman P. "Andrés Bello y José Victorino Lastarria: conflicto de generaciones y tensiones intelectuales". Cuadernos Americanos 62 (1997): 183-213.

Unzueta, Fernando. "Bello, la nueva conciencia histórica y los discursos poscoloniales". Andrés Bello y los Estudios Latinoamericanos. Pittsburg: Instituto Internacional de Literatura Iberoamericana, 2009. 219-43.

Woll, Allen L. A functional past. The uses of history in nineteenth-century Chile. Louisiana and London: Louisiana State University Press, 1982. 